British Journal of Psychiatry (1988), 152, 289-298

\title{
Correspondence
}

Editor: Greg Wilkinson

Contents: Late paraphrenia/Lithium in the treatment of aggression in mentally handicapped patients: a double-blind trial/Peer-group support for patients in the community/P3 and CT scan in patients with chronic schizophrenia/Alcohol and ageing/Constant current vs constant voltage ECT devices/Clonidine and neuroleptic-resistant mania/Khat-induced paranoid psychosis/Psychiatry and Glasnost/Urinary tribulin output in patients with panic attacks/ HLA-DR2 and sleep onset REM periods in endogenous depression/Mystical-ecstatic and trance states/Unilateral auditory hallucinations.

\section{Late Paraphrenia}

SIR: Professor Levy and his colleagues say I am "unshakeable" and "unduly dogmatic" (Journal, November 1987, 151, 702). Let us examine the facts. My paper (Grahame, 1984) compared the symptom profile of a group of patients with various research diagnostic criteria for schizophrenia. The majority of patients fulfilled three of the four criteria, which would suggest that it is reasonable to include late paraphrenia within the group of schizophrenias. I concede that to say the results of that study "confirms that late paraphrenia is one of the schizophrenias" may be overstating the case. Attentive reading of p. 494 of the same paper should clarify my position with regard to first rank symptoms.

Professor Levy and colleagues imagine that I believe that minor cognitive changes and ventricular enlargement in a group of schizophrenic patients suggests "that this was a harbinger of "organic brain syndrome' ". Holden (Journal, May 1987, 150, 635-639) states, "Thirteen cases, progressing to dementia within three years, according to their clinical state and mental test scores, were incorporated into an 'organic' group..." It would seem therefore that it is he, rather than me, who suggests that late paraphrenia is a harbinger of organic brain syndrome.

Attentive reading of my letter (Journal, August $1987,151,268$ ) shows that I quote Blessed \& Christie (1982) implicity agreeing with the view that func- tional illness in old age is not a harbinger of organic brain disease.

Attentive reading of Holden's paper indicates that "interview was possible in 14 of the 20 cases alive at 10 years" and that "the patient's interview was carried out using an open-ended clinical interview, covering the current mental state and the history wherever possible". I assumed that meant that Holden had personally interviewed 14 patients. If that assumption is wrong, I stand corrected.

The hypothesis I support, yet to be disproved, is that the term 'late paraphrenia' should be reserved for the functional group of non-affective paranoid illness, which Holden actually gives support to. Perhaps "unshakeable in his belief" and "unduly dogmatic attitudes" are as much features of De Crespigny Park as they are of Colchester!

\section{Severalls Hospital \\ Boxted Road, \\ Colchester CO4 5 HG}

\section{References}

BLESSED, G. \& WILSON, I. D. (1982) The contemporary natural history of mental disorder in old age. British Journal of Psychiatry. 141, 59-67.

GRAHAME, P. S. (1984) Schizophrenia in old age (late paraphrenia). British Journal of Psychiatry, 145, 493-495.

Lithium in the Treatment of Aggression in Mentally Handicapped Patients: A Double-Blind Trial

SIR: The fact that Craft et al (Journal, May 1987, $150,685-689$ ) used the 5-point rating scale for aggression is of interest. No scale to measure aggression for use in this type of patient was suitable when the scale was formulated in 1980. The scale was adapted from those used for each individual in an earlier study (Dale, 1980). However, it has never been possible, with the resources available in this hospital, to test for inter-rater reliability. It is now clear that Craft $e t$ al did this before using the scale in their multi-centre trial, and found it statistically reliable. The scale is simple to use and administer. In these 
days when trained nursing staff in institutions for these patients are getting fewer, it is important that any recording method is reliable but not timeconsuming. This scale is now seen to fulfil these criteria.

No claim is made by the authors that the scale could not be improved, nor that it could not be completed during more regular intervals during the 24 hours, giving a more complete record of a patient's behaviour. Clearly it could be so used, and this would answer one of the points in the letter criticising the trial's design (Journal, November 1987, 151, 705706). Any scale, no matter how unsophisticated it may appear and even be, is better than none and I, for one, am grateful for the efforts undertaken by Dr Craft and his colleagues in proving the validity of it despite its imperfections. Included in my gratitude are the unnamed nurse assessors who administered the scale during both its verification and use.

Coldeast Hospital

P. G. DAle

Sarisbury Green

Southampton SO3 6ZD

\section{Reference}

DALE. P. G. (1980) Lithium therapy in aggressive mentally subnormal patients. British Journal of Psychiatry, 137, 469-474.

\section{Peer-Group Support for Patients in the Community}

SIR: Ford et al (Journal, October 1987, 151, 479-485) make a valuable statement when they claim that resettlement of "those (patients) currently remaining in hospital will require increasingly extensive provision". However, it is difficult to equate the variables they have measured with the resources and handicaps the patients actually have.

As an illustration of this criticism, the authors have determined how many patients go outside the hospital and how many have visitors. In my experience, patients with no contacts outside the hospital may still have valuable friendships within the hospital. For example, some patients, while not legally married, form stable heterosexual partnerships which are loving and supportive. In Sheffield, longstay patients are being resettled in the community in social groups. This appears to be successful in that it makes the move less frightening and helps reduce post-discharge loneliness. Peer-group support gives the patients the confidence to become friendly with local people in the street, shop, and public house. Several patients for whom previous discharge plans broke down have been enabled to live outside this way.
Interested relatives and friends outside the hospital can provide valuable support; however, even patients without them should not necessarily be considered friendless. As patients left in hospital have fewer supports and resources it is important that we mobilise the ones they do have to best effect.

\section{Rehabilitation Unit \\ Middlewood Hospital \\ Sheffield S6 ITP}

\section{P3 and CT Scan in Patients with Chronic Schizophrenia}

SIR: We read with interest the paper by Romani et al (Journal, October 1987, 151, 506-513). Using a similar auditory discrimination task in a group of 21 DSM-III diagnosed schizophrenic out-patients and short-term in-patients (Ebmeier et al, 1987), we also found reduced P3-amplitudes in patients compared with age-matched controls. Neither history of potential perinatal brain damage, nor-as found by Romani et al-psychiatric family history was correlated with P3-amplitude or P-latency within the schizophrenic group. For our patients, calculated means of P3-latencies were about 20 ms longer than for controls, although this difference did not reach significance if $\mathrm{P} 3$ was defined as the largest peak between 260 and $450 \mathrm{~ms}$ post-stimulus.

Increased latencies of $\mathrm{P} 3$ have been reported only by a small sub-group of investigators, most recently by Blackwood et al (1987). Baribeau-Braun et al (1983) incidentally do not report increased latencies, as suggested by Romani et al. Possible additional confounding factors will therefore have to be considered. The obvious one is that schizophrenic patients agreeing to ERP studies are a (self-)selected group which might differ from study to study. Romani et al's patients were receiving "monotherapy" with haloperidol. In the absence of a disclaimer it has to be assumed that anticholinergic drugs were prescribed to at least some of the patients. Callaway (1984) described an increase of P3-latency after scopolamine, and in our patient group P3-latency was correlated significantly with dose of anticholinergic medication (Kendall's $\tau=0.48, P<0.01$ ). We agree with Romani et al that neuroleptic medication is unlikely to account for $\mathrm{P} 3$ changes. Blackwood et al (1987) found no intra-subject differences before and after initiation of neuroleptic drug therapy, and for our patients there was no correlation between dose of neuroleptic (in chlorpromazine units) and P3-latency or amplitude. Pfefferbaum et al (1984) did not report an absence of a neuroleptic drug effect on ERPs as suggested by Romani et al. 